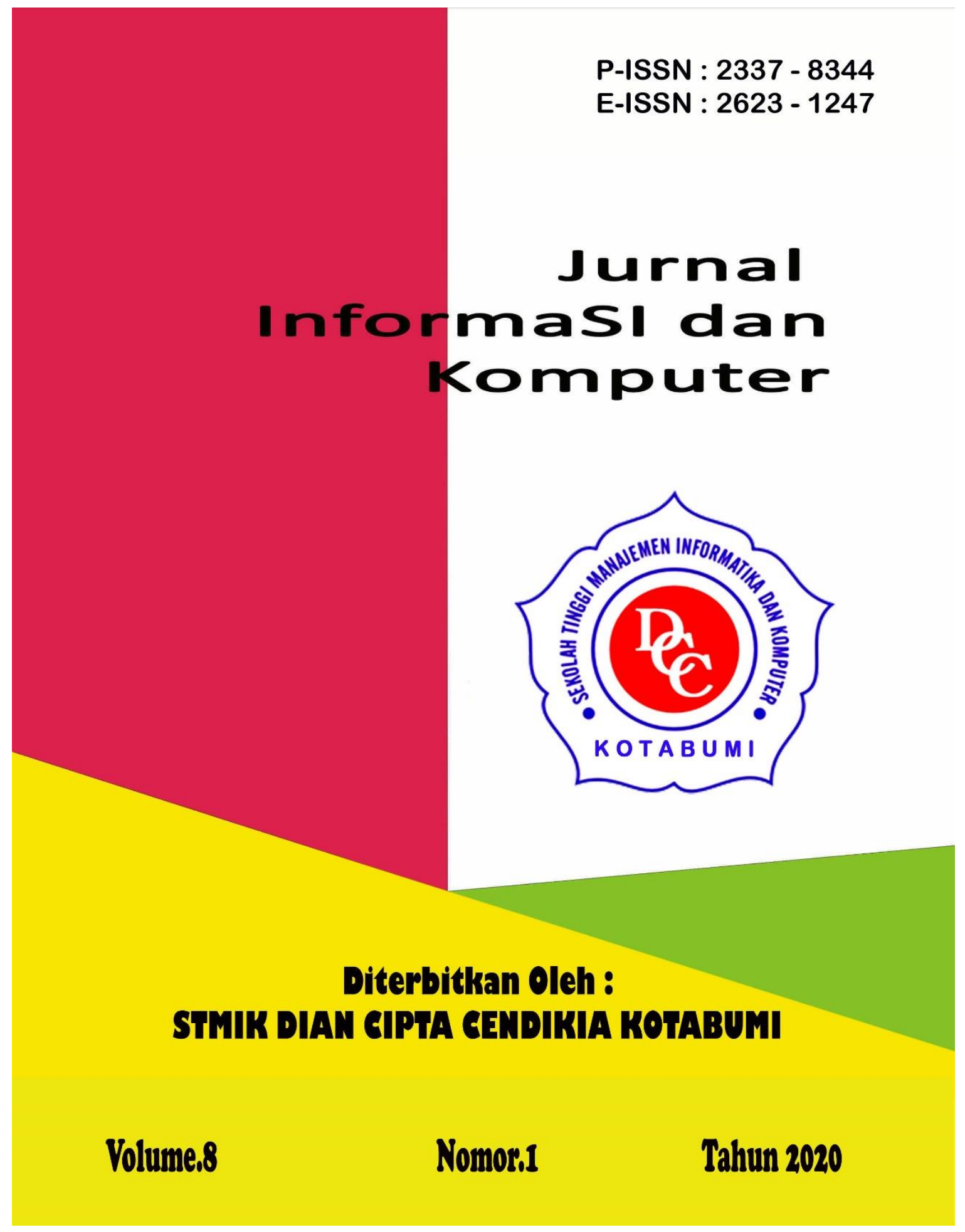


Penerbit:

STMIK DIAN CIPTA CENDIKIA KOTABUMI

Bekerjasama dengan LPPM STMIK DCC Kotabumi

Hak atas naskah/tulisan tetap berada pada penulis, isi diluar tanggung jawab

Penerbit dan Dewan Penyunting

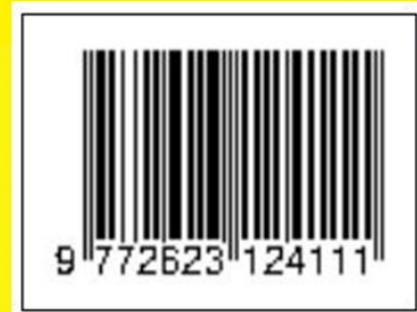




\section{PENGANTAR REDAKSI}

Puji syukur dipanjatkan kehadirat Tuhan Yang Maha Esa, atas karunia dan limpahan rahmatNYA jualah Jurnal Informatika dan komputer (InfoKom) STMIK Dian Cipta Cendikia Kotabumi ini dapat terwujud.Jurnal Informatika dan Komputer (InfoKom) yang terbit dua (2) kali dalam setahun ini merupakan suatu wadah untuk penyebar luasan hasil-hasil penelitian, studi pustaka, karya ilmiah yangberkaitan dengan Informatika dan Komputer khususnya bagi dosen-dosen STMIK Dian Cipta Cendikia Kotabumi serta umumnya para cendikiawan, praktisi, peneliti ilmu Informatika dan Komputer.

Harapan, dengan diterbitkannya Jurnal Informatika dan Komputer (InfoKom) ini sebagai salah satu bentuk sumbangan pemikiran dalam pengembangan ilmu informatika dan komputer yang berkaitan dengan kajian-kajian di bidang tekhnologi Informatik, Komunikasi Data dan Jaringan Komputer, perancangan dan Rekayasa Perangkat Lunak, serta ilmu-ilmu yang terkait dengan bidang Informatika dan Komputer lainnya.

Berkenaan dengan harapan tersebut, kepada para peneliti, dosen dan praktisi yang memiliki hasil-hasil penelitian, kajian pustaka, karya ilmiah dalam bidang tersebut diatas, dengan bangga redaksi Jurnal Informatika dan Komputer (JIK) menerima naskah ringkasan untuk dimuat pada jurnal Informatika dan Komputer (InfoKom) STMIK Dian Cipta Cendikia Kotabumi dengan berpedoman pada penulisan naskah jurnal sebagaimana dilampirkan pada halaman belakang (Bagian kulit dalam) buku jurnal ini.

Mutu dari suatu jurnal ilmiah tidak hanya ditentukan oleh para pengelolanya saja, tetapi para penulis dan pembaca jualah yang mempunyai peranan besar dalam meningkatkan mutu jurnal Informatika dan Komputer ini. Merujuk pada realita ini kamu sangat mengharapkan peran aktif dari peneliti untuk bersama-sama menjaga dan memelihara keberlangsungan dari jurnal Informatika dan Komputer STMIK Dian Cipta Cendikia Kotabumi ini. Yang juga tidak kalah pentingnya dari partisipasi tersebut diatas, adalah saran dan kritik yang membangun dari pembaca yang budiman agar kiranya dapat disampaikan langsung kepada redaksi JIK. Saran dan kritik yang membangun akan dijadikan masukan dan pertimbangan yang sangat berarti guna peningkatan mutu dan kualitas Jurnal Informatika dan Komputer STMIK Dian Cipta Cendikia Kotabumi.

Tak lupa diucapkan terima kasih yang tak terhingga atas perhatian dan kerjasama dari semua pihak yang tak dapat disebutkan satu persatu hingga dapat diterbitkan nya Jurnal Informatika dan Komputer (InfoKom) STMIK Dian Cipta Cendikia Kotabumi. Semoga apa yang telah diperbuat untuk kebaikan akan menjadi amal ibadah, amin.

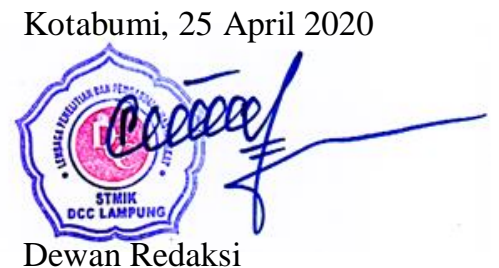




\section{JURNAL INFORMASI DAN KOMPUTER}

Volume 8 Nomor 1 April 2020

Jurnal Informasi dan Komputer merupakan Sarana informasi ilmu pengetahuan, Tekhnologi dan Komunikasi yang berupa hasil penelitian, tulisan ilmiah, Ataupun studi pustaka. Jurnal ini terbit dua kali setahun pada bulan April dan Oktober. Berisi hasil penelitian ilmiah di bidang informatika yang bertujuan untuk menghubungkan adanya kesenjangan antar kemajuan teknologi dan hasil penelitian. Jurnal ini di terbitkan pertama kali pada tahun 2013.

Penanggung Jawab:

Ketua STMIK Dian Cipta Cendikia

Kotabumi

\section{Pembina:}

Ketua STMIK Dian Cipta Cendikia

Kotabumi

Ketua Lembaga Penelitian STMIK Dian

Cipta Cendikia Kotabumi

\section{Pimpinan Redaksi}

Dwi Marisa Efendi,.S.Kom.,M.Ti

\section{Redaksi pelaksana}

Rustam,.S.Kom,.M.Ti (STMIK Dian

Cipta Cendikia Kotabumi)

Nurmayanti M.Kom (STMIK Dian

Cipta Cendikia Kotabumi)

Sukatmi,.S.Kom., M.Kom (AMIK DCC

Bandar Lampung)

Sampurna Dadi Riskiono,M.Kom

(Universitas Teknokrat Indonesia)

Ifo Wahyu

Pratama,S.Kom.,M.Ti(AMIK MASTER

Lampung)

\section{Mitra Bestari}

Merri Parida.,M.Kom (STMIK Dian

Cipta Cendikia Kotabumi)

Amarudin,S.Kom.,M.Eng (Universitas

Teknokrat Indonesia)

Didi Susianto.,S.T.,M.Kom (AMIK

DCC Bandar Lampung)

Alhibarsyah.,S.T.,M.Kom (Stmik Tunas

Bangsa Bandar Lampung)

Kemal Farouq Mauladi

.,S.Kom.,M.Kom (Universitas Islam

Lamongan)

Agus Setiawan S.Pd.,M.Eng

(Universitas Muhammadiyah

Lamongan)

Penerbit : STMIK Dian Cipta Cendikia Kotabumi Bekerja Sama Dengan LPPM STMIK Dian Cipta Cendikia Kotabumi.

\section{Alamat Redaksi/Penerbit:}

Jl. Negara No. 3 Candimas Kotabumi

Lampung Utara

No Telpon/Fax 072423003

Email :1ppm-stmik@dcc.ac.id 


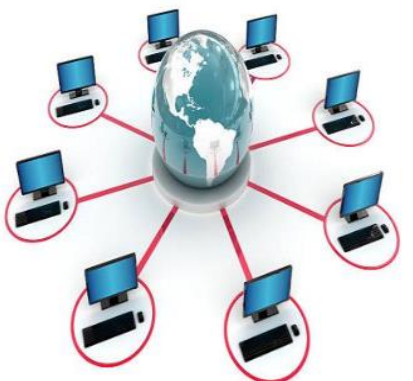 \\ JURNAL INFORMASI DAN KOMPUTER VOL. 8 NO. 1 THN. 2020}

\section{DAFTAR ISI}

\section{Halaman}

Sistem Pendukung Keputusan Penentuan Lahan Kopi Terbaik Dengan Metode

Ahp (Analytic Hierarchy Process)

Sidik Rahmatullah, Rendy Abdurahman (AMIKKOM Jogja,

STMIK Dian Cipta Cendikia Kotabumi)

Rancang Bangun Sistem Informasi Pada Program Pembangunan Pemberdayaan

Masyarakat Desa( P3md ) Berbasis Web Mobile

Ferly Ardhy, Firmansyah, Sidik Rahmatullah,(IIB Darma Jaya Bandar Lampung

STMIK Dian Cipta Cendikia Kotabumi, AMIKKOM Jogja)

Sistem Informasi Pengolahan Data Alumni Sekolah Menengah Atas (Sma)

Merri Parida, Nindiya Ova Rahmawati (AMIKKOM Jogja,

STMIK Dian Cipta Cendikia Kotabumi)

SISTEM INFORMASI GEOGRAFIS PUSKESMAS BESERTA SARANA

DAN PRASARANA BERBASIS WEB MOBILE

Nurmayanti, Windy Dwi Bahari (AMIKOM Jogja,

STMIK Dian Cipta Cendikia Kotabumi)

Rancang Bangun Sistem Informasi Konseling Untuk Sekolah Menengah Kejuruan

(Smk) Berbasis Website

Aliy Hafiz1, Galih Rakasiwi, Ifo Wahyu Pratama, Agus Komarudin,

Bambang Suparapto, Fathurrahman Kurniawan Ikhsan

(AMIK Dian Cipta Cendikia Bandar Lampung,

Universitas Nahdhatul Ulama Lampung, AMIK Dian Cipta Cendikia Pringsewu,

Universitas Mitra Indonesia, Lampung) .....

Sistem Pendukung Keputusan Pemilihan Driver Terbaik Menggunakan Metode

Weight Product (Wp)

Dina Lorenza, Pitrawati (STMIK Dian Cipta Cendikia Kotabumi

AMIK Dian Cipta Cendikia)

Rancang Bangun Sistem Informasi Pembayaran Mahasiswa

Darsin(Universitas Megou pak Tulang Bawang)

Sistem Informasi Geografis Bengkel Motor Honda Resmi Bandar Lampung

Sukatmi, Nuraini (AMIK Dian Cipta Cendikia Bandar Lampung).....

Sistem Pakar Diagnosa Penyakit Kulit Wajah Dengan Metode

Certainty Factor Pada Klinik Skin Rachel

Dwi Marisa Efendi, Putri Yulita Sari (IIB Darmajaya Bandar Lampung,

STMIK Dian Cipta Cendikia Kotabumi) 
Sistem Informasi Monitoring Siswa Pada Mts Al-Islamiah Bunut Kabupaten Pesawaran Yuli Syafitri ${ }^{2}$, Reni Astika ${ }^{1}$, Septian Hernando $^{3}$ AMIK Dian Cipta Cendikia

Aplikasi Kamus Bahasa Jepang Berbasis Mobile Android

Rustam $^{2}$, A Yanda Febry Pangestu ${ }^{2}$ Sistem Informasi, Teknologi Komputer ${ }^{1}$, IIB Darmajaya

Bandar Lampung ${ }^{2}$ STMIK Dian Cipta Cendikia Kotabumi 


\title{
RANCANG BANGUN SISTEM INFORMASI PEMBAYARAN MAHASISWA
}

\author{
Darsin \\ Teknik Informatika \\ Universitas Megou Pak Tulang Bawang \\ Lampung \\ Jl. Lintas Timur Sumatera Tiuh Tohou Menggala - Tulang Bawang \\ E-mail : umptb.darsin@gmail.com
}

\begin{abstract}
ABSTRAK
Universitas Megou Pak Tulang Bawang merupakan salah satu instansi yang bergerak di bidang pendidikan tinggi. Saat ini sistem pengolahan data yang digunakan khususnya pengolahan data pembayaran masih di lakukan dengan menggunakan program terapan dan belum digunakannya format database. Adapun pencarian data yang telah dimasukkan masih sulit disajikan karena data disimpan secara manual (data dalam bentuk arsip), sehingga terdapat kendala yang dihadapi seperti : proses pencarian data, perubahan data maupun rekap laporan masih membutuhkan waktu yang relatif lama dan memungkinkan terjadinya kesalahan (human error) karena rekap data dilakukan berdasarkan arsip.sehingga di butuh Sistem aplikasi yang baru dalam pengolahan data pembayaran pada Universitas Megoupak merupakan sarana yang diharapkan dapat membantu dalam proses penginputan data pembayaran, yang meliputi menu input data jurusan, mahasiswa, rincian biaya dan pembayaran. Selain itu juga merancang laporan data mahasiswa, dan laporan data pembayaran.
\end{abstract}

Kata Kunci : data pembayaran, mahasiswa UMPTB

\begin{abstract}
Universitas Megou Pak Tulang Bawang is one of the institutions engaged in higher education. Currently the data processing system used in particular payment data processing is still being done using an applied program and the database format is not yet used. The search for data that has been entered is still difficult to be presented because the data is stored manually (data in the form of an archive), so there are obstacles faced such as: the process of finding data, changing data and report recap still requires a relatively long time and allows errors (human error)) because the data recap is based on archives. So a new application system is needed in processing payment data at the University of Megoupak which is expected to help in the process of inputting payment data, which includes menu input data for majors, students, details of fees and payments. It also designs student data reports, and payment data reports.
\end{abstract}

Keywords: payment data, UMPTB students

\section{PENDAHULUAN}

Universitas Megou Pak Tulang Bawang merupakan salah satu instansi yang bergerak di bidang pendidikan tinggi. Saat ini sistem pengolahan data yang digunakan khususnya pengolahan data pembayaran masih di lakukan dengan menggunakan program terapan dan belum digunakannya format database. Adapun pencarian data yang telah dimasukkan masih sulit disajikan karena data disimpan secara manual (data dalam bentuk arsip), sehingga terdapat kendala yang dihadapi seperti : proses pencarian data, perubahan data maupun rekap laporan masih membutuhkan waktu yang relatif lama dan memungkinkan terjadinya kesalahan (human error) karena rekap data dilakukan berdasarkan arsip.

Untuk mengatasi masalah tersebut perlu diusulkan suatu sistem baru yang dapat membantu memberikan peningkatan efektifitas dalam pembuatan laporan juga mampu memberikan suatu informasi yang baik, akurat, cepat dan tepat waktu. Informasi merupakan suatu hal yang sangat penting dan besar sekali pengaruhnya dengan 
informasi yang tepat seseorang dapat membantu suatu perencanaan yang lebih baik, sehingga penulis membuat judul "Rancang Bangun Sistem Informasi Pembayaran di Universitas Megou Pak Tulang Bawang"

\subsection{Identifikasi Masalah}

Berdasarkan latar belakang yang telah dikemukakan diatas, penulis dapat mengidentifikasi masalah yang terjadi sebagai berikut :

a. Belum adanya pengolahan data pembayaran.

b. Proses pembuatan laporan pembayaran, tunggakan maupun rincian pembayaran dilakukan secara manual sehingga hasil yang disajikan relatif lama.

c. Terjadinya penumpukan arsip yang memungkinkan hilangnya arsip sehingga akan menyulitkan dalam pembuatan laporanlaporan yang diperlukan

\subsection{Rumusan Masalah}

Berdasarkan latar belakang masalah diatas, maka penulis merumuskan masalah sebagai berikut "bagaimana merancang sistem pembayaran pada Universitas Megou Pak Tulang Bawang" sehingga dapat melayani mahasiswa dengan baik dan dapat memperoleh data lebih cepat dan akurat.

\subsection{Batasan Masalah}

Agar penelitian yang dilakukan tidak menyimpang dari permasalahan yang akan dibahas, maka penulis membatasi ruang lingkup masalah yang akan dibahas sebagai berikut :

a. Pengolahan data pembayaran berbasis jaringan (network)

b. Menggunakan bahasa pemograman Visual Basic 6.0 dan database SQL Server 2000.

\section{Tinjauan Pustaka}

\subsection{Pengertian Rancang Bangun}

Rancangan sistem adalah penentuan proses dan data yang diperlukan oleh sistem baru (McLeod, 2002). Perancangan adalah kegiatan yang memiliki tujuan untuk mendesain sistem baru yang dapat menyelesaikan masalah-masalah yang dihadapi perusahaan yang diperoleh dari pemilihan alternatif sistem yang terbaik (Ladjamudin, 2005). Sedangkan pengertian bangun atau pembangunan sistem adalah kegiatan menciptakan sistem baru maupun mengganti atau memperbaiki sistem yang telah ada baik secara keseluruhan maupun sebagian (Pressman, 2002). Bangun sistem adalah membangun sistem informasi dan komponen yang didasarkan pada spesifikasi desain (Whitten et al, 2004).

\subsection{Pengertian Sistem Informasi}

Didefinisikan oleh Leitch Robert.A dan K.Roscoe Davis yang disadur oleh H.M Jogiyanto (2005: 11)

"Sistem informasi adalah suatu sistem didalam suatu organisasi yang mempertemukan kebutuhan pengolahan transaksi harian, mendukung operasi, bersifat menejerial dan kegiatan strategi dari suatu organisasi dan menyediakan pihak luar tertentu dengan laporan-laporan yang diperlukan".

\subsection{Pengertian Pembayaran}

Pembayaran adalah pemindahan dana guna memenuhi suatu kewajiban yang timbul dari suatu kegiatan ekonomi. H.M Jogiyanto (2010: 171)

\subsection{Pengertian Mahasiswa}

Secara harfiah, mahasiswa adalah orang yang belajar di perguruan tinggi, baik di universitas, institut, maupun akademi. Menurut Kamus Bahasa Indonesia (2008), Definisi mahasiswa adalah orang yang belajar di perguruan tinggi. Setelah menyelesaikan pendidikan di bangku sekolah, sebagian siswa ada yang menganggur, mencari pekerjaan, atau melanjutkan pendidikan ke tingkat perguruan tinggi. Mereka yang terdaftar sebagai murid di perguruan tinggi dapat disebut sebagai mahasiswa (Takwin, 2008).

\section{METODOLOGI PENELITIAN}

\subsection{Metode Pengumpulan Data}

Metode yang digunakan dalam menyusun serta melengkapi data yang di gunakan adalah melalui proses wawancara, studi pustakan dan observasi.

\subsection{Metode Pengembangan Sistem}

Metode pengembangan sistem yang digunakan adalah Siklus Hidup Pengembangan Sistem (System Development Life Cylce) yang terdiri 
dari beberapa tahapan-tahapan yang sangat penting dalam keberadaan perangkat lunak yang dilihat dari segi pengembangannya. SDLC menggunakan model Waterfall seperti pada Gambar 1

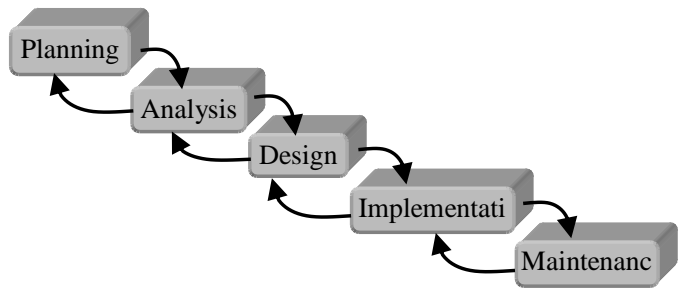

Gambar 1 Metode Pengembangan Model Waterfal

\section{HASIL DAN PEMBAHASAN}

Kontek Diagram yang di usulkan

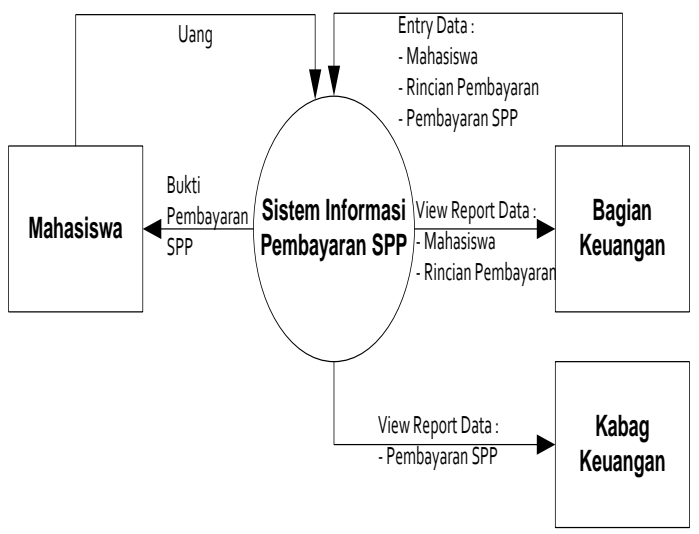

Gambar 2 Kontek Diagram

\section{Data Flow Diagram}

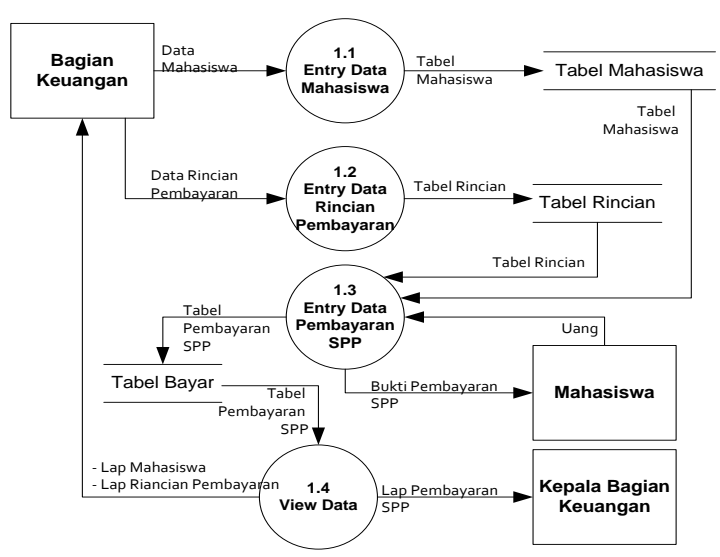

Gambar 3 Data Flow Diagram

\section{Pembahansan Program Menu Utama}

Dalam menu utama ini berisikan menu, yaitu menu master, menu transaksi, menu laporan dan keluar, gambar selengkapnya ditunjukkan pada gambar 4.1.

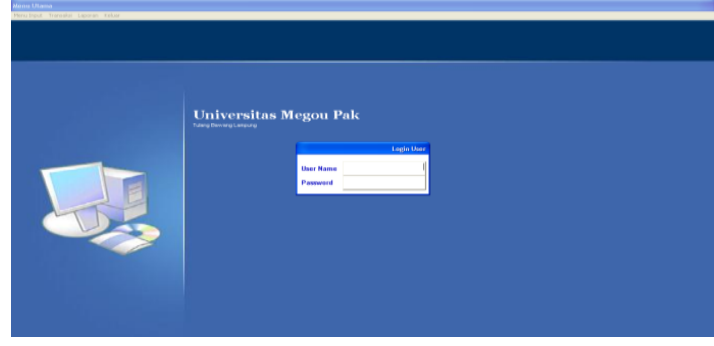

Gambar 4.1 Menu Utama

\section{Menu Input}

Submenu ini digunakan untuk mengakses form inputan data Jurusan, input data mahasiswa dan input data rincian biaya. Selengkapnya dtunjukkan pada gambar 4.2.

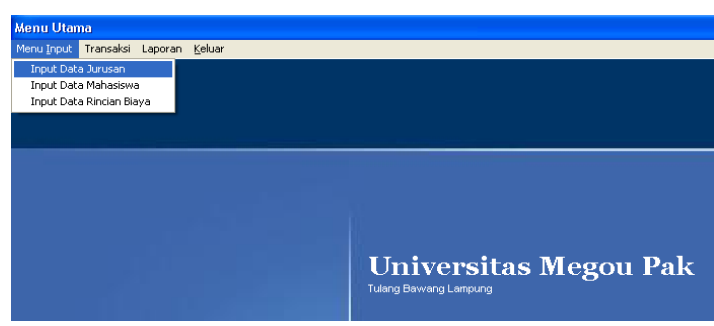

Gambar 4.2 Menu Master

\section{Sub Menu Input Data Jurusan}

Membuka form submenu data input jurusan dimulai dengan memilih menu data master kemudian data input Mahasiswa pada menu utama. Sub menu Entry data jurusan digunakan untuk meng-Input data jurusan yang ditunjukkan pada gambar 4.3.

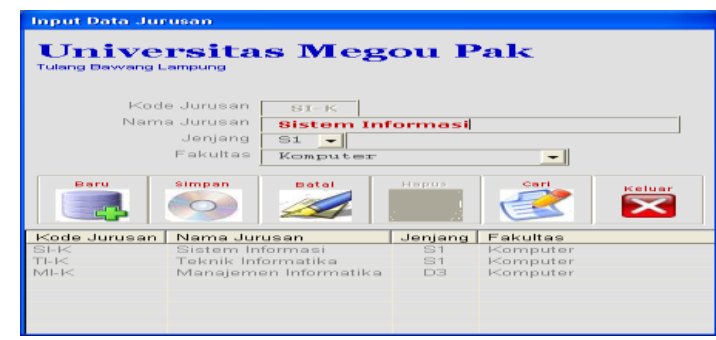

Gambar 4.3 Menu Entry Data Jurusan 


\section{Sub Menu Input Data Mahasiswa}

Sub menu Entry data Mahasiswa digunakan untuk meng-Input data Mahasiswa yang ditunjukkan pada gambar 4.4.

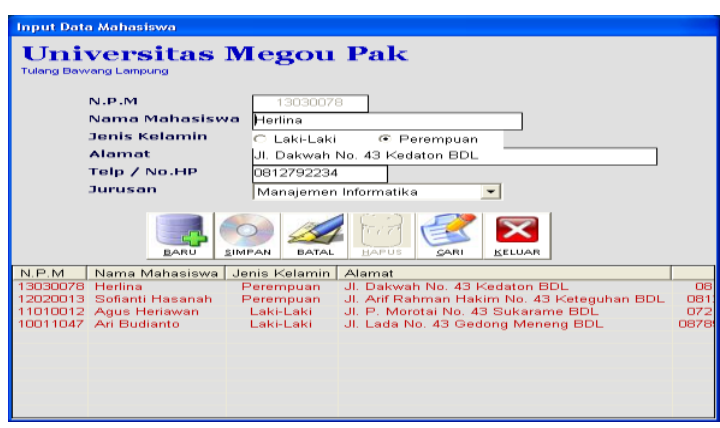

Gambar 4.4 Menu Entry Data Mahasiswa

\section{Sub Menu Input Data Rincian Biaya}

Sub menu Entry data rincian biaya digunakan untuk meng-Input data rincian biaya yang ditunjukkan pada gambar 4.5.

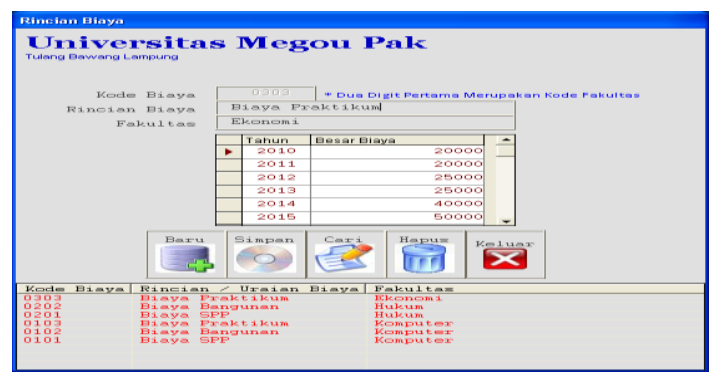

Gambar 4.5 Menu Entry Data Rincian Biaya

\section{Menu Transaksi}

Pada menu data terdapat sub menu yaitu data transaksi pembayaran. Submenu ini digunakan untuk mengakses form transaksi pembayaran. Selengkapnya ditunjukkan pada gambar 4.6.

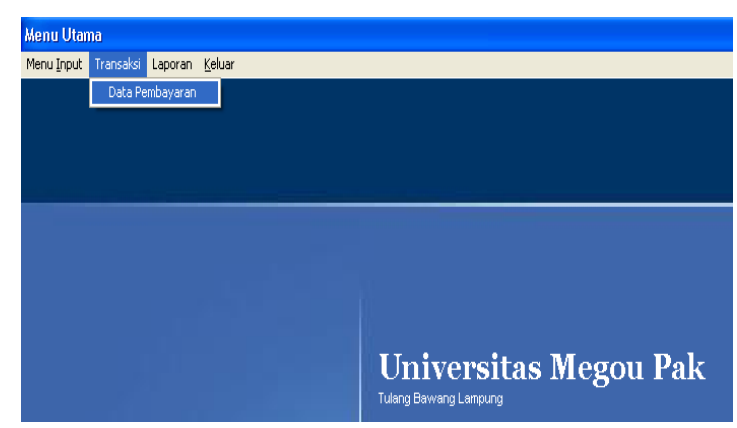

Gambar 4.6 Menu Transaksi

\section{Sub Menu Transaksi Pembayaran}

Sub menu transaksi pembayaran digunakan untuk meng-input data pembayaran yang ditunjukkan pada gambar 4.7.

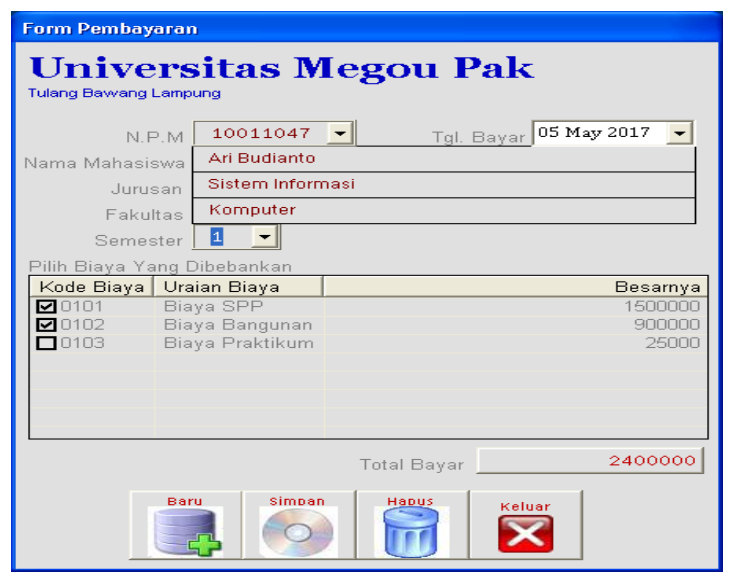

Gambar 4.7 Sub Menu Transaksi Pembayaran

\section{Menu Laporan}

Pada menu laporan terdapat submenu yaitu laporan data mahasiswa dan laporan data pembayaran. Submenu ini digunakan untuk mengakses form output laporan data mahasiswa dan laporan pembayaran. Selengkapnya ditunjukkan pada gambar 4.8 .

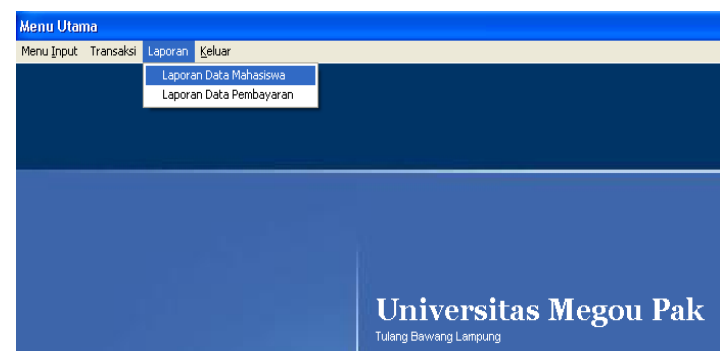

Gambar 4.8 Menu Laporan

\section{Sub Menu Laporan Data Mahasiswa}

submenu laporan data seperti ditunjukkan pada gambar 4.9.

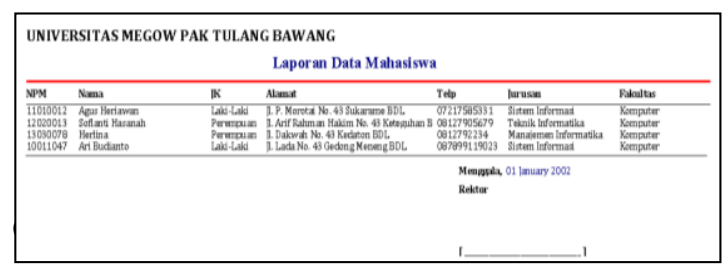

\section{Sub Menu Laporan Data Pembayaran}


submenu laporan pembayaran seperti ditunjukkan pada gambar 4.10.

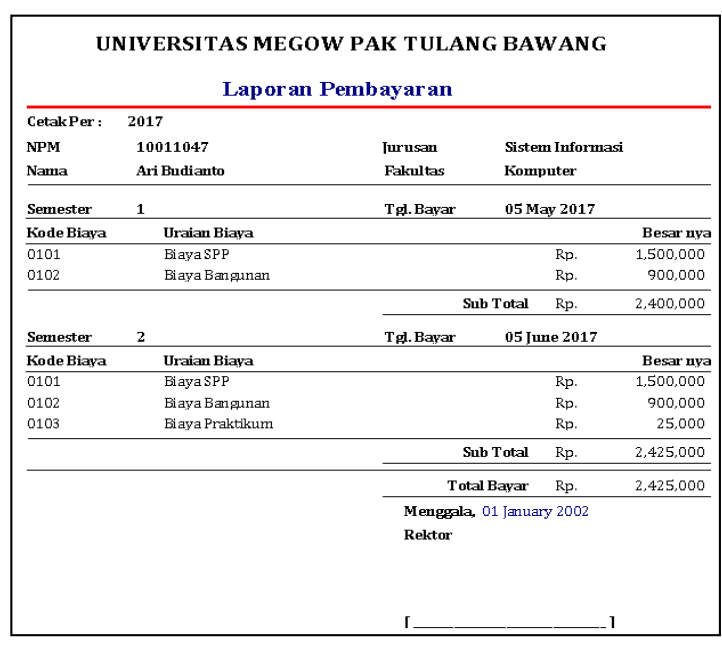

Gambar 4.10 Hasil Print Laporan Data Pembayaran

\section{KESIMPULAN DAN SARAN}

\subsection{Kesimpulan}

Berdasarkan pada bab-bab sebelumnya, maka penulis mengambil kesimpulan sebagai berikut: Sistem aplikasi yang baru dalam pengolahan data pembayaran pada Universitas Megoupak merupakan sarana yang diharapkan dapat membantu dalam proses penginputan data pembayaran, yang meliputi menu input data jurusan, mahasiswa, rincian biaya dan pembayaran. Selain itu juga merancang laporan data mahasiswa, dan laporan data pembayaran.

\subsection{Saran}

Di samping beberapa kesimpulan tersebut, penulis juga mencoba memberikan saran yang diharapkan dapat bermanfaat bagi Universitas Megoupak, adapun saran tersebut adalah:

a. Universitas Megoupak hendaknya dapat menggunakan sistem informasi yang diusulkan untuk proses pengolahan data pembayaran karena kemampuan kerja aplikasi ini lebih baik.

b. Agar Aplikasi ini dapat berjalan dan berfungsi sebagaimana mestinya, maka diperlukan tenaga pelaksana, pelatihan untuk pengoprasian aplikasi tersebut.

c. Untuk keamanan sebuah data diperlukan back-up data dan keamanan data (security).
[1] Agus, Lahinta. (2009). Konsep Rancangan Sistem Pendukung Keputusan Penentuan Kandidat Penerima Beasiswa (Studi Kasus pada TPSDM Propinsi Gorontalo). Diambil tanggal 12 November 2016 dari pukul 06.30 http://wances.net46.net/files/jurnal/ Agus\%20Lahinta.pdf.

[2] Jogiyanto, 2005, Analisis \& Desain Sistem Informasi pendekatan Terstruktur, Andi Offset, Yogyakarta.

[3] Kristanto Andri, 2007, Perancangan Sistem Informasi dan Aplikasinya, GAVA MEDIA, Yogyakarta.

[4] Linda Marlinda, 2005, Sistem Basis Data, Andi Yogyakarta.

[5] Pranata, Antony. 2005. Algoritma dan Pemograman Borland Delphi. JJ Learning Yogyakarta.

[6] Takwin, B. (2008). Menjadi mahasiswa. Bagustakwin http://www.landasanteori.com/2015/ 09/pengertian-mahasiswa-definisi menurut.html (Diakses pada tanggal 28 November 2016).

[7] Thomas L Saaty, 2000 "The Fundamentals of Decision Making and Priority Theory with the Analytic Hierarchy Process" Vol. VI of the AHP Series, Andi Offset : Yogyakarta.

[8] Turban Efraim, Aronson Jay E, Liang Ting Peng, 2005 “ Decision Support Systems and Intelegent Systems" edisi 7 Jilid 1, Andi Offset : Yogyakarta.

\section{DAFTAR PUSTAKA}

